\title{
História das disciplinas escolares e história da educação: algumas reflexões*
}

\author{
Marcílio Souza Júnior \\ Universidade de Pernambuco \\ Ana Maria de Oliveira Galvão \\ Universidade Federal de Minas Gerais
}

\author{
Correspondência: \\ Marcílio Souza Junior \\ Rua Silvino Lopes, n. 125/804 - \\ Casa Forte \\ 52061-490 - Recife - PE \\ e-mail: m.souzajr@uol.com.br
}

\footnotetext{
* Os autores agradecem a Ceres Leite Prado pela leitura crítica deste artigo.
}

\section{Resumo}

No contexto de renovação da historiografia da educação no Brasil, tem sido crescente o número de estudos que buscam compreender como determinados saberes se tornaram propriamente escolares. Essas pesquisas têm contribuído para um melhor entendimento do papel desempenhado pela escola e por outras instâncias sociais na definição daquilo que, ao longo do tempo, tem sido considerado essencial na formação das novas gerações. Esse campo de estudos tem sido identificado ao que se convencionou denominar História das Disciplinas Escolares, uma abordagem multidisciplinar que, já há algumas décadas, vem sendo desenvolvida por pesquisadores de vários países do mundo. 0 artigo, que constitui um ensaio bibliográfico, busca identificar e problematizar tendências de pesquisa nessa área no interior do campo mais amplo da História da Educação. Por fim, descreve sucintamente dois estudos realizados recentemente por pesquisadores brasileiros nas áreas da Educação Física e Educação Artística, que se inserem nessa linha de investigação. Apesar do crescente número de pesquisas realizadas em torno do tema, a maioria dos trabalhos, muitas vezes dedicados a traçar cronológica e retroativamente a presença de um saber na escola, é realizada de forma isolada e parte de pressupostos - muitas vezes rígidos - advindos das tradições da transposição didática ou da cultura escolar. Acredita-se que somente com a realização periódica de balanços é possível tornar inteligível o processo de transformação e/ou construção de saberes em saberes propriamente escolares tanto em uma perspectiva empírica quanto do ponto de vista propriamente teórico.

\section{Palavras-chave}

Historiografia da educação - Disciplinas escolares - Educação física - Educação artística. 


\title{
History of school subjects and history of education: some reflections*
}

\author{
Marcílio Souza Júnior \\ Universidade de Pernambuco \\ Ana Maria de Oliveira Galvão \\ Universidade Federal de Minas Gerais
}

Contact:

Marcílio Souza Junior

Rua Silvino Lopes, n. 125/804 -

Casa Forte

52061-490 - Recife - PE

e-mail: m.souzajr@uol.com.br

* The authors wish to thank Ceres
Leite Prado for the critical review
of this article.

\begin{abstract}
In the context of a renovation of the historiography of education in Brazil, there have been a growing number of studies trying to understand how certain knowledges became school knowledges proper. These studies have contributed to improve our understanding about the role played by the school and by other social organizations in the definition of what has been regarded at different times as essential in the formation of the new generations. This field of study has been identified to what has been called History of School Subjects, a multidisciplinary approach that has been developed by researchers around the world during the last decades. The article constitutes a bibliographical essay, and seeks to identify and problematize research trends in this area within the wider field of the History of Education. Lastly, it briefly describes two studies carried out recently by Brazilian researchers in the areas of Physical Education and Artistic Education that can be included in this line of investigation. Despite the rising number of studies carried out around this topic, the majority of works, often dedicated to outline chronologically and retrospectively the presence of a specific knowledge at school, are conducted in isolation, and adopt assumptions - many times rigidly - coming from the didactic transposition or school culture traditions. We believe that it is only by conducting periodic assessments that the process of transformation and/or construction of knowledges into school knowledges proper can be made intelligible, both from an empirical perspective and from a theoretical point of view.
\end{abstract}

\section{Keywords}

Historiography of education - School subjects - Physical education - Artistic education. 


\section{Introdução}

Nas últimas duas décadas no Brasil, no contexto de renovação da historiografia da educação no país ${ }^{1}$, tem sido crescente o número de estudos que buscam compreender como determinados saberes se tornaram propriamente escolares. Em geral realizadas por professores/pesquisadores interessados em conhecer a história de sua própria disciplina, essas pesquisas têm contribuído, de maneira significativa, para um melhor entendimento do papel desempenhado pela escola e por outras instâncias sociais na definição daquilo que, ao longo do tempo, tem sido considerado essencial na formação das novas gerações. Esse campo de estudos tem sido identificado, de modo geral, no interior da história da educação, ao que se convencionou denominar História das Disciplinas Escolares, uma abordagem multidisciplinar que, já há algumas décadas, vem sendo desenvolvida por pesquisadores de vários países do mundo.

Certamente um dos motivos pelos quais a História das Disciplinas Escolares tem se configurado, na atualidade brasileira, como uma importante área de estudos tem sido a sua potencialidade em fornecer um novo olhar para a escola do passado, permitindo perceber que a história da educação vai além da história dos ideários e dos discursos pedagógicos. Estudos nesse campo permitem, ainda, complexificar a noção de tempo, na medida em que o estudo das transformações de um saber que se torna escolar não obedece a uma linearidade lógica, mas resulta de uma série de injunções que assumem características específicas em cada espaço social e em cada época.

Nesse texto, buscamos identificar e problematizar tendências de pesquisa nessa área no interior do campo mais amplo da História da Educação, embora reconhecendo sua vinculação também com outras tradições de investigação, como a Sociologia do Currículo. Descrevemos ainda, sucintamente, dois estudos realizados recentemente por pesquisadores brasileiros que se inserem nessa linha de investigação.

\section{História das disciplinas escolares}

História das Disciplinas Escolares, História das Disciplinas Curriculares, História das Matérias Escolares, História dos Saberes Escolares, História dos Conteúdos Escolares são expressões que remetem a um mesmo campo de pesquisa.

Os estudos em História das Disciplinas Escolares aparecem, segundo Bittencourt, em diferentes países quase que simultaneamente, possuindo em comum a preocupação em

identificar a gênese e os diferentes momentos históricos em que se constituem os saberes escolares, visando perceber a sua dinâmica, as continuidades e descontinuidades no processo de escolarização. (2003, p. 15)

Chervel (1990) afirma que a especificidade desse campo de estudos reside na investigação dos ensinos da idade escolar, pois o seu elemento central é a história dos conteúdos. Nesse campo, é possível investigar a relação entre o que foi estabelecido como finalidade para os conteúdos de ensino e o que foi efetivamente ensinado/ aprendido. Enfim, não é um campo que estuda a história das idéias pedagógicas, do discurso pedagógico oficial, das políticas educacionais, já que tais elaborações visam mais freqüentemente, em geral de forma positiva, corrigir um estado de coisas, modificando certas práticas, do que propriamente representar a realidade. Por outro lado, o campo da História das Disciplinas Escolares procura enfatizar o porquê de a escola ensinar o que ensina, em vez de tentar responder o que a escola deveria ensinar.

Para Forquin (1992), esse campo de pesquisa possibilita obter informações acerca da seleção cultural que faz a escola, identificando o que é, em determinada época, compreendido

1. Para um mapeamento recente do campo da História da Educação no Brasil, ver, entre outros, Vidal e Faria Filho (2003), Carvalho (2004), Lopes e Galvão (2001). 
como o que deve ser ensinado. É possível também, nesse campo, captar elementos que, em um conflituoso percurso de conquista de legitimidade de uma ou outra disciplina curricular, mostrem a conquista de um estatuto, a briga por recursos, as delimitações territoriais no interior do currículo escolar, os espaços nos horários etc.

0 próprio de uma reflexão sociológica ou histórica sobre os saberes escolares é contribuir para dissolver esta percepção natural das coisas, ao mostrar como os conteúdos e os modos de programação didática dos saberes escolares se inscrevem, de um lado, na configuração de um campo escolar caracterizado pela existência de imperativos funcionais específicos (conflitos de interesses corporativos, disputas de fronteiras entre as disciplinas, lutas pela conquista da autonomia ou da hegemonia no que con-cerne ao controle do currículo), de outro lado na configuração de um campo social caracterizado pela coexistência de grupos sociais com interesses divergentes e com postulações ideológicas e culturais heterogêneas, para os quais a escolarização constitui um trunfo social, político e simbólico. (Forquin, 1992, p. 43-44)

Para Goodson (1995), a História das Matérias Escolares, compondo a área da História do Currículo, propõe-se a penetrar em um campo que os historiadores se mostraram inclinados a ignorar: os conteúdos escolares, os métodos de ensino e os percursos de estudo, buscando nos processos internos da escola (caixa-preta) pistas para analisar as complexas relações entre escola e sociedade, inclusive enfatizando como as escolas tanto refletem como refratam as definições da sociedade acerca dos conhecimentos culturalmente válidos. Tal área de estudo passa a estabelecer um novo paradigma para os estudos sobre a História da Educação, trazendo uma agenda que aproxima os estudos educacionais dos estudos da história do conhecimento:
Todavia, o seu valor principal reside em sua capacidade de investigar a realidade interna e a autonomia relativa da escolarização. A história curricular considera a escola algo mais do que um simples instrumento de cultura da classe dominante. (Goodson, 1995, p. 120)

Nesse sentido, Santos (1990) afirma que a História das Disciplinas Escolares representa uma reação aos trabalhos em que a educação é quase exclusivamente interpretada em função da estrutura econômica, política e social:

Essa nova área de estudos, no campo da sociologia do currículo, tem como objetivo explicar a emergência e evolução das diferentes disciplinas escolares. Além disso, investiga também a predominância de certas tendências durante um determinado período, bem como mudanças na organização e estruturação do conteúdo e nos métodos de ensino. (ibid. p. 21-22)

Procura-se, desse modo, compreender a busca por legitimidade de algumas disciplinas escolares consideradas de menor valor pedagógico; investigar a constituição do estatuto epistemológico de tais disciplinas; pesquisar o movimento de transformação da cultura e, mais especificamente, do conhecimento científico em saber escolar; e observar as modificações dos métodos e conteúdos de ensino ao longo do tempo, abrangendo diferentes períodos.

A História das Disciplinas Escolares tende ainda a focalizar o seu olhar para as características peculiares de cada nível e modalidade de ensino: do elementar, passando pelo secundário e indo até o superior, no que se inclui inclusive, segundo Bittencourt (2003), compreender as diferenças entre eles e o processo de transformação dos conhecimentos das disciplinas acadêmicas universitárias em conteúdos das disciplinas/matérias escolares do currículo da educação básica.

Nesse sentido, o currículo é considerado uma palavra-chave, segundo Goodson (1995), para melhor compreender a escola ao longo do 
tempo. Currículo escrito, currículo como fato, currículo como prática, currículo como atividade são algumas entre as várias denominações e concepções atribuídas ao termo. Goodson (1995), porém, conclui que a luta por definir o que é currículo termina por caracterizá-lo como sendo a invenção de uma tradição ${ }^{2}$.

Desse modo, o que chamamos por currículo e por disciplina/matéria escolar nem sempre teve a compreensão que contemporaneamente lhes atribuímos, tanto nos seus sentidos mais corriqueiros quanto em uma concepção mais acadêmica. Com o objetivo de rever brevemente a história da compreensão conceitual de currículo e disciplina escolar, revisemos alguns conceitos atribuídos a tais termos, procurando assim evitar um problema comum nas pesquisas históricas - o anacronismo.

0 termo currículo advém da palavra latina scurrere, que pode ser traduzida como correr, referindo-se a curso a ser seguido, mais especificamente a ser apresentado (Goodson, 1995). Provavelmente a compreensão mais antiga do termo currículo foi encontrada em fontes da Universidade de Glasgow, na Escócia em 1663, que lhe atribui o significado de atestado de graduação outorgado a um mestre dessa instituição de ensino (Goodson, 1995; Saviani, 1994). Segundo Nereide Saviani, com o tempo

o termo currículo evolui da idéia inicial de registro de vida estudantil de cada aluno [...] para indicar o conjunto dos "novos traços ordenados e seqüenciais da escola do século XVI'. (1994, p. 41)

$\mathrm{Na}$ atualidade, num sentido mais corrente, o currículo passa a ser compreendido como um conjunto daquilo que se ensina e daquilo que se aprende, tendo como referência alguma ordem de progressão, podendo referir-se para além do que está escrito/prescrito oficialmente (Forquin, 1996).

0 currículo pode também ser considerado como um processo informal de interação entre aquilo que é deliberado, o que é interpretado e o que é efetivado, às vezes de maneira transformada ou até mesmo subvertida (Goodson, 1995).
Enfim, o currículo amplia o sentido de organização disciplinar, no sentido de regras de conduta, para o sentido de organização disciplinar, compreendendo objetos, partes e matérias do ensino.

Já o termo disciplina, no sentido de conteúdos de ensino, segundo Chervel (1990), só aparece mais recentemente - nas primeiras décadas do século $X X-$, pois até o fim do século XIX, seu significado não era mais do que a vigilância dos estabelecimentos em relação às condutas prejudiciais a sua boa ordem e àquela parte da educação dos alunos que contribui para tal ordem, podendo se identificar a atitudes repressivas ou ainda fazendo par com o verbo disciplinar, que é sinônimo de ginástica (exercício) intelectual. Os termos que equivaleriam à disciplina, durante o século XIX, como conteúdos de ensino, eram: objetos, partes, ramos ou ainda matérias de ensino.

É após a $1^{\text {a }}$ Guerra Mundial que o termo disciplina vai tornar-se uma rubrica que classifica as matérias de ensino, dando um caráter aos conteúdos, como sendo próprios do ambiente escolar, mas não se desvinculando por completo de seu sentido de exercitação intelectual, já que é acompanhado por métodos e regras para abordar os diferentes domínios do pensamento, do conhecimento e da arte (Chervel, 1990).

0 entendimento do termo disciplina está vinculado à idéia de hierarquização e estratificação. Porém, ao contrário do que se estabelece nas escolas atuais, a idade nem sempre foi critério de repartições por níveis. Nossa atual estrutura de classes (baseada em faixas etárias) é resultante da forma mais pedagógica da organização das escolas do século XVIIl, influenciada pela estrutura das escolas cristãs e pelo ensino mútuo, pois até então a maioria delas se organizava em classe única, em que a con-

2. Para Hobsbawn e Ranger (1984, p. 1), autores no qual Goodson se baseia, o termo "tradição inventada significa um conjunto de práticas e ritos: práticas normalmente regidas por normas expressas ou tacitamente aceitas; ritos - ou natureza simbólica — que procuram fazer circular certos valores e normas de comportamento mediante repetição, que automaticamente implica em continuidade com o passado. De fato, onde é possivel, o que tais práticas e ritos buscam é estabelecer continuidade com um passado histórico apropriado". 
sideração da idade não desempenhava nenhum papel direto nas repartições escolares. Chegava a existir uma variação de até doze anos numa mesma repartição (Chervel, 1990). Esse processo adquire uma face específica na história da educação brasileira, na medida em que, embora o método simultâneo já fosse recomendado pelas instâncias oficiais de educação desde meados do século XIX, o ensino seriado só foi oficialmente implantado com a criação dos grupos escolares no início do período republicano (ver Faria Filho, 2000; Faria Filho; Vidal, 2000; Souza, 1998; Pinheiro, 2002).

Segundo Goodson (1995), as matérias (disciplinas) escolares passam por uma seqüência de estágios. Elas partem de um momento de marginalidade com um status inferior no currículo, passam para um estágio utilitário e finalmente alcançam uma definição como disciplina, que se configuraria a partir de um conjunto exato e rigoroso de conhecimentos.

O que apenas pretendemos dizer é que a aplicação explicitamente instrumental de conjuntos de conhecimentos diminui em relação inversa à seriedade e ao êxito das tentativas dos profissionais de melhorar as suas condições materiais. (Goodson, 1995, p. 131)

Layton (apud Goodson, 1990), analisando a evolução da matéria (disciplina) Ciências no currículo escolar, define três estágios. No primeiro, a matéria, ainda intrusa, conquista lugar no horário escolar e justifica sua presença por sua utilidade. Nesse momento, os alunos são atraídos para a matéria por ela estabelecer relações com questões do interesse deles. Os professores não são especialistas da área, mas entusiastas pioneiros. No segundo, já começam a surgir uma tradição de trabalho acadêmico e um conjunto de especialistas treinados. Os alunos agora são atraídos também pelo crescente status acadêmico. A seleção e a organização de seus conteúdos são mais influenciadas por sua lógica interna. E, no terceiro e último, os professores já constituem um quadro profissional com regras e valores estabelecidos. Os conteúdos selecionados para a matéria advêm, em grande medida, dos acadêmicos da área. Os alunos começam a iniciar-se em uma tradição e aproximar-se, portanto, da passividade.

Segundo Santos (1990), se o estabelecimento de uma disciplina depende também de fatores internos - tais como a emergência de grupos de liderança intelectual, o surgimento de centros acadêmicos de prestígio na formação de profissionais, a organização e a evolução das associações de profissionais e o avanço da política editorial da área - então, às influências sociais e econômicas, não se podem atribuir simples e diretamente as conformações e transformações ocorridas no âmbito educa-cional. A autora ainda afirma que é fundamental reconhecer que as relações entre os fatores internos e externos, no desenvolvimento de uma disciplina, não são uma constante, pois o peso desses fatores dependerá de algumas condições. E alerta que se devem observar o nível e o tipo de desenvolvimento de um país, principalmente seu regime político, pois ele pode ter grande peso nesse processo, podendo tornar uma disciplina mais vulnerável aos fatores externos. Enfim

quanto maior é o nível de maturidade de uma disciplina e a organização dos profissionais da área, maior será o peso dos fatores internos no seu desenvolvimento. (Santos, 1990, p. 26)

Como pode ser visto, as disciplinas escolares não se estabelecem no currículo escolar de maneira pacífica, conformando-se às orientações oficiais, mas ao contrário, guardam relações conflituosas com as teorizações acadêmicas e as recomendações oficiais, ora acatando-as, ora resistindo a elas, ora reformando-as ou deformando-as.

\section{A história da educação no Brasil e o estudo das disciplinas escolares}

No caso específico da história da educação brasileira, as idéias sinteticamente expos- 
tas acima penetraram e foram reelaboradas no campo a partir de um movimento mais amplo de renovação dos seus objetos e fontes. Nesse processo, alguns conceitos e/ou teorizações elaborados nas áreas de educação e/ou de história foram de fundamental importância na realização das pesquisas.

Por muito tempo, a história da educação, no Brasil e também em outros países (ver Compère, 1995), ocupou-se de estudar a organização dos sistemas de ensino e de ideário e discursos pedagógicos, baseando-se em fontes como leis, regulamentos, reformas educacionais e obras de grandes pensadores. Em virtude de sua aproximação com a filosofia da educação, essa história se tornou, muitas vezes, um estudo das recomendações. A história da educação tratou muito pouco, até recentemente, das práticas escolares e do cotidiano escolar, pois, via de regra, procurou obter de tais fontes e objetos como o passado educacional se projetou. Nesse sentido, configurou-se como uma história do que deveria ser a realidade e não do que a realidade efetivamente foi (Lopes e Galvão, 2001). Evidentemente, não estamos nos referindo aqui à ilusão rankeana ${ }^{3}$ de trazer ao presente o passado tal como ele realmente aconteceu, mas à tentativa de (re)construir práticas educativas e não apenas proposições educacionais.

Muitas vezes pautados em uma concepção de história positivista, os trabalhos tradicionalmente realizados no campo da história da educação deixaram mais evidentes a história política, a história das intenções dos sujeitos civis (pensadores) e dos sujeitos políticos (Estado). Muitas dessas pesquisas tiveram como objetivo a descrição de fatos notáveis e a ação dos sujeitos - quase identificados como personagens heróicos -, em um tempo histórico linear, ordenado de maneira cronológica e sucessiva a partir de uma lógica formal.

No entanto, nos últimos tempos, a história da educação passou por um verdadeiro processo de renovação. No Brasil, especificamente nos últimos vinte anos, esse campo de estudos aproximou-se de uma nova forma de escrever a história, possibilitando uma nova leitura principalmente da escola. Segundo Lopes e Galvão (2001), os estudos passaram a ser mais localizados e contextualizados, lidando com períodos de tempo mais curtos. Ainda segundo as autoras, essa área passou a se preocupar com a organização e o funcionamento interno das escolas, com a expressão e/ou construção cultural no cotidiano escolar, com o estabelecimento do conhecimento, do currículo, das disciplinas escolares. Além das fontes oficiais, que têm recebido um novo olhar e um novo tratamento, outras fontes passaram a ser utilizadas, tais como a fotografia, a literatura, os manuais escolares, os jornais e revistas, a "história" oral ${ }^{4}$ etc.

Esse movimento de renovação e ampliação na historiografia da história da educação vai encontrar inspiração, sobretudo, na Escola dos Annales, uma nova forma de entender e escrever a história que posteriormente se convencionou chamar de Nova História. Segundo Burke (1997), as idéias diretrizes dos Annales, sumária e brevemente, buscam substituir a narrativa tradicional de acontecimentos por uma história-problema; descrever/reconhecer a história para além dos fatos políticos, buscando os elementos de todas as atividades humanas; e integrar a história com outras disciplinas das Ciências Sociais. No interior da Nova História, um campo específico de estudos tem atraído a atenção dos historiadores da educação: a História Cultural que, como veremos adiante, vai também influenciar a investigação sobre a História das Disciplinas Escolares.

No interior desse processo de renovação, como já referido, a História das Disciplinas tem se tornado uma área privilegiada de investigação. Identificamos, no caso da história da educação brasileira, três conceitos nucleares e/ou tendências teóricas que parecem ter influenci-

3. Referimo-nos, aqui, a Leopold Ranke (1795-1886) que, na tentativa de dar à história um estatuto de ciência, acreditava que cabia aos historiadores, mediante a pesquisa em documentos oficiais, escrever sobre o passado tal como ele realmente havia acontecido.

4. Como advogam Amado e Ferreira (1996), a fonte oral não constitui, por si só, história. Assim, usamos o termo entre aspas para indicar sua filiação teórico-metodológica, mas reconhecendo que a fala do sujeito da pesquisa é apenas uma fonte como tantas outras. 
ado decisivamente as pesquisas desenvolvidas no país ${ }^{5}$.

Uma primeira influência advém das teorizações e pesquisas realizadas no campo da Sociologia do Currículo ou da Nova Sociologia da Educação e tem como referência, principalmente, as investigações de Michael Young realizadas na Inglaterra. É importante frisar, no entanto, que tal perspectiva é originária fundamentalmente da inspiração dos estudos de Le Play realizados já na virada do século. Nos anos 60 do século XX, os estudos de Raymond Williams, por sua vez, fornecem um referencial para uma abordagem que reconhece a cultura como uma tradição seletiva, ou seja, como um processo de decantação e reinterpretação permanente da herança deixada pelas gerações anteriores. Já no fim dos anos de 1960 e início dos de 1970, Forquin (1996) identifica uma outra abordagem que tem como um de seus representantes Frank Musgrove. Este centraliza seus estudos na natureza social das construções curriculares, verificando como as matérias escolares conferem a seus membros um forte sentimento de identidade. Já a partir de meados dos anos de 1970, identifica o que se chamou Nova Sociologia da Educação ${ }^{6}$ que associa os estudos acerca do currículo a um programa de crítica político-cultural radical, procurando evidenciar como se dava o processo de legitimação dos conteúdos curriculares e da estratificação dos saberes. Pode-se afirmar assim que, no âmbito da sociologia educacional, os estudos, apesar de existirem, apresentaram um desenvolvimento incipiente até o fim da década de 1950, conquistando mais fôlego a partir dos anos de 1970, quando, então, passam a constituir uma nova sociologia da educação, tendo como objeto central de suas teorizações o currículo escolar (Moreira; Silva, 1995).

As pesquisas nesse campo têm como foco central a análise do processo de seleção e organização do conhecimento educacional e, mais especificamente, do saber escolar, buscando compreender como o conhecimento é materializado no currículo. No percurso de uma reconceitualização de currículo, aparecem estudos que, examinando as relações entre ele e a estrutura social (cultura, poder, ideologia, controle social), procuram focalizar como fazer o currículo trabalhar a favor dos grupos e das classes oprimidas, desenvolvendo assim seu potencial libertador.

Forquin (1996) identifica, ainda, um outro grupo que teve um papel fundamental nos estudos sociológicos sobre currículo: trata-se dos pesquisadores que investigam a relação entre currículo formal, currículo real e currículo oculto. Na França, o autor evidencia que a discussão acerca do currículo acontece mais tardiamente do que na Inglaterra, no início dos anos de 1980. Isso se dá porque a reflexão sobre programas de ensino foi conduzida no quadro de uma tradição enciclopédica, em que os saberes escolares eram considerados como naturais, portanto, sem merecer reflexão e questionamento. Já em meados da década de 1980, é possível encontrar estudos que estabelecem diferenças entre o currículo formal/oficial e o currículo real, entendendo-se este último como aquilo que é realmente ensinado nas salas de aula, passivel de ser conhecido por observação ou pesquisa direta com os professores e alunos. Nessa mesma época, é possível observar uma outra abordagem, mais precisamente em países anglófonos. São os estudos que focalizam as discussões em torno do currículo oculto, ou seja, naquilo que está implícito, invisível na organização curricular, desde a estruturação do tempo e espaço escolar até a codificação. 0 implícito pode suscitar o desenvolvimento de competências favoráveis ou mesmo ações dissimuláveis e pervertidas.

Uma segunda influência que pode ser detectada na realização das pesquisas sobre a História das Disciplinas Escolares no âmbito da

5. Jean Hébrard identifica, ainda, a influência da história das ciências, que no caso da História da Educação brasileira parece não ter tido grande penetração. Ver Oliveira (2003).

6. Para o autor, uma afirmação de Bernstein resume muito bem a hipótese central na Nova Sociologia da Educação: "o modo como uma sociedade seleciona, classifica, distribui, transmite e avalia os saberes destinados ao ensino reflete a distribuição do poder em seu interior e a maneira pela qual aí se encontra assegurado o controle social dos comportamentos individuais" (Bernstein apud Forquin, 1993, p. 85). 
história da educação brasileira advém de dois conceitos que, em sua origem, apresentaram-se como antagônicos: o de transposição didática cujo principal representante é Yves Chevallard e o de cultura escolar - elaborado principalmente por André Chervel. Forquin (1996) identifica a elaboração desses conceitos no interior de uma discussão entre historiadores, didaticistas e sociólogos.

Em uma primeira abordagem, aparecem recentemente, na França, estudos de didaticistas que compreendem disciplina escolar como transposição didática ${ }^{7}$. Usando tal noção, os pesquisadores passam a investigar o percurso do saber até chegar à escola, ou seja, a transformação do conhecimento científico exterior à escola em conhecimento escolar. Apesar de recente, essa abordagem se baseia no conceito de transposição didática elaborado já em 1975, a partir dos estudos do sociólogo Michel Verret. Influenciada por pesquisas de diversos estudiosos, principalmente aqueles vinculados ao IREM (Institute de Recherches en Education Mathématique), essa abordagem dá origem à Teoria das Situações Didáticas, com fundamentos em um campo de conhecimento denominado Engenharia Didática ${ }^{8}$. Numa espécie de "cooperativa teórica”, a Teoria das Situações Didáticas tem como referência estudos de Jean Piaget, Gérard Vergnaud, Guy Brousseau, Yves Chevellard, Regine Douady, Aline Robert e outros.

Em uma outra abordagem, fazendo uma crítica rigorosa à primeira, encontram-se os estudos históricos que mostram que a escola não se contenta em transpor os conteúdos preexistentes e exteriores a ela. Nesses estudos, investiga-se a escola como local de produção do conhecimento com características originais, ou seja, a compreensão de disciplina escolar como cultura escolar ${ }^{9}$. André Chervel investiga a constituição de um corpo de conhecimentos que chama de gramática escolar, construído por pedagogos para servirem de apoio às aprendizagens das regras ortográficas. Analisando o ensino de francês na França, o autor discorda da abordagem da transposição didática e afir- ma que as disciplinas escolares possuem uma autonomia, gerando um conhecimento pedagógico próprio da escola. As disciplinas escolares, apesar de seus conteúdos de ensino terem origem na sociedade e na cultura que rodeiam a escola, não se ligam diretamente às ciências de referência, pois se assim fosse, seria dada à pedagogia a característica de um simples método. Chervel (1990) denomina esse processo de disciplina-vulgarização, em que a disciplina simplifica (vulgariza) os saberes, e ainda de pedagogia-lubrificante, em que a pedagogia se encarrega de lubrificar e fazer girar a máquina educacional.

Hébrard (1999) assim resume esse debate entre as duas abordagens:

[...] hoje, o principal debate desse domínio refere-se às relações entre saberes eruditos e saberes escolares. Para certos autores (modelo da transposição didática), os sistemas escolares são percebidos como dispositivos que selecionam e transformam os saberes produzidos pelos 'intelectuais' com a finalidade de torná-los assimiláveis pelos novos alunos. Para outros (modelo da história das disciplinas escolares), a escola constrói seus próprios tipos de saberes ou habilidades conforme os modos de elaboração, cuja lógica pode ser encontrada dentro dos próprios sistemas educativos. É o caso, por exemplo, das gramáticas escolares, que durante muito tempo

7. Por transposição didática, entende-se "o conjunto de transformações que sofre o saber científico, antes de ser ensinado. Da escoIha do saber a ensinar à sua adaptação ao sistema didático, existe todo um processo gerador de deformações, de estabelecimento de coerência e até de criação de novos conhecimentos, que culmina com o que se chama de saber escolar, enunciado nos programas e, particularmente, observáveis nos livros-texto" (Chevallard, 1985).

8. Estudos que buscam a criação e a exploração de situações de aprendizagem sobre temas específicos de ensino e que visam à validação de certas construções empíricas extraídas de inovações pedagógicas (Henry, 1992).

9. Por cultura escolar, Dominique Julia entende "um conjunto de normas que definem conhecimentos a ensinar e condutas a inculcar, e um conjunto de práticas que permitem a transmissão desses conhecimentos e a incorporação desses comportamentos; normas e práticas coordenadas a finalidades que podem variar segundo as épocas (finalidades religiosas, sócio-políticas ou simplesmente de socialização)" (2001, p. 10). 
não se beneficiaram dos avanços da filologia ou das ciências da linguagem e dificilmente aceitaram esse enxerto quando a ocasião se apresentou. (p. 35-36)

É importante observar que o debate entre, de um lado, as exigências de didatização do saber científico para tornar-se saber escolar e, de outro, do papel ativo desempenhado pela escola na criação de saberes já está presente nas instâncias educacionais brasileiras há, pelo menos, mais de um século. Galvão et al (2003), analisando livros escolares e pareceres sobre livros conferidos por instâncias oficiais da província de Pernambuco no século XIX, constataram, por exemplo, que muitos aspectos que, na atualidade, estão no centro da discussão sobre os processos de escolarização dos saberes já estavam em pauta naquele momento e espaço social. Destacam-se, nesse sentido, as relações entre conhecimento científico, saberes da tradição que circulavam fora da escola e o processo de didatização dos saberes pela instituição escolar.

De acordo com as instâncias educacionais da época, para um livro ter seu uso aprovado nas aulas de primeiras letras da província, os conteúdos deveriam ser consistentes do ponto de vista científico. Não seriam admitidos livros que trouxessem inexatidões ou desatualizações muito gritantes em relação ao conhecimento que era produzido no âmbito da ciência. Esse critério não foi atendido, por exemplo, pela obra Compendio de Physica para Leituras, de autoria de Francisco de Paula Barros, destinada às escolas de instrução primária, que recebeu, em 1885, parecer não favorável do Conselho Literário para que fosse utilizada nas escolas provinciais. Um dos principais argumentos dos pareceristas refere-se justamente às "inexactidões e faltas da doutrina compendiada”. Ao longo do parecer, são apresentados os diversos erros conceituais cometidos pelo autor que parece não ter incorporado minimamente as diversas descobertas que realizavam as ciências naquele vertiginoso final de século. Embora reconheçam que o conhecimento científico sofre transformações muito rápidas e que é difícil para um livro escolar acompanhar essas transformações, os pareceristas não perdoam os diversos erros cometidos - onze, no total, são elencados, destacando-se as imprecisões científicas dos conceitos utilizados e enfatizando-se as contradições apresentadas pelo próprio compêndio. Como afirmam os pareceristas:

Os brilhantes e numerosos progressos da physica nas suas theorias, e principalmente as suas portentosas descobertas na ordem pratica, teem nestes ultimos annos preocupado por tal modo a attenção publica, que são por toda parte recibidos com verdadeira anciedade as publicações, que tem por fim compendiar sob uma forma succinta e em linguagem dos que não são profissionaes, os principios mais fundamentaes, os factos mais incontestaveis e as applicações multi-plices de tão importante dominio dos conhecimentos humanos - Á vista do movimento universal das sciencias physicas e no meios das modificações mais ou menos profundas, porem sempre progressivas, que ellas vão diariamente soffrendo, os tratados elementares, mesmo os mais bem accabados, são sempre incompletos; porque, por mais exactos que sejão os quadros, que elles apresentão dos conhecimentos actuaes, poucos mezes bastão para que se tornem esses quadros insufficientes e até infieis. (APEJE: IP 44, 1885, p. 66-67)

Para os autores do parecer, no entanto, os erros apontados

são graves e não convem por forma alguma que figurem em um compendio de physica, sciencia hoje tão necessaria que o seu estudo faz parte de todos os programmas de ensino desde a escola primaria até os cursos superiores. (APEJE: IP 44, 1885, p. 66-67).

Pode-se perceber, assim, que havia uma preocupação para que a escola estivesse atualizada em relação às então recentes descober- 
tas científicas. Nesse sentido, o livro deveria funcionar como uma espécie de mediador entre o conhecimento científico e as exigências de didatização.

Para que uma obra fosse considerada didática, por outro lado, precisava necessariamente adequar-se ao público a que se destinava: as crianças das escolas primárias. Nesse sentido, em vários momentos, os pareceristas qualificam esse público chamando a atenção para a necessidade de que o livro alcance as inteligências "mais incultas ou débeis" (APEJE: IP 19, 1866, p. 294) dos meninos e meninas.

Além disso, para atender às exigências de "didatização", o livro escolar também deveria ser bem organizado. Para ser aprovado, este deveria apresentar uma seqüência lógica, não ser confuso, ser claro/breve, metodicamente planejado e adequado ao uso escolar. Na segunda metade dos oitocentos, os manuais também deveriam se basear nos preceitos do método intuitivo ${ }^{10}$ : suas páginas deveriam coadunar-se com um espírito mais prático do que teórico e, entre os recursos possíveis para que isso ocorresse, recomendava-se o uso de desenhos, exercícios e quadros. Percebe-se, nesse aspecto, a consciência que tinham os que estavam à frente das instâncias de instrução pública provinciais de que o conhecimento científico era distinto do conhecimento escolar. Cabia ao manual mediar essas duas instâncias: se, como vimos, o manual deveria estar isento de imprecisões e inexatidões científicas, também deveria adequar-se ao uso cotidiano da escola e ao público ao qual se destinava. Assim, a preocupação com a "transposição didática”, para usar uma expressão de cem anos depois (Chevallard, 1985), parecia presente não apenas restrita ao manual escolar, mas a toda ação da escola, pelo menos no final do século, quando a discussão sobre o método intuitivo e a "lição de coisas" tornam-se cada vez mais presentes.

Uma terceira influência que se pode identificar nesses estudos mais recentes que se debruçam sobre os saberes e disciplinas esco- lares no campo da história da educação brasileira advém da história cultural, que tem chamado atenção principalmente por meio dos estudos de Roger Chartier (1990), "para a necessidade de se estudarem os objetos culturais em sua materialidade, restabelecendo os processos implicados em sua produção, circulação, consumo, práticas, usos e apropriações" (Lopes e Galvão, 2001, p. 40).

Segundo Jean Hébrard (1999), a história cultural debruçou-se também sobre os processos de escolarização, mas segundo uma outra perspectiva. Para essa tendência, um dos maiores problemas colocados pelas diferentes sociedades é a história das relações entre culturas orais e culturas escritas. Nesse sentido, a escola não pode ser considerada o único nem o mais importante lugar "onde se constroem e transmitem os equipamentos intelectuais de uma sociedade" (p. 37). No entanto, ela desempenha um papel importante na definição desses equipamentos, sobretudo quando "enuncia as normas legítimas do seu uso" ( $p$. 37), favorecendo ou freando a sua divulgação em grupos sociais diferentes. Nesse sentido, segundo o autor, a investigação sobre a História das Disciplinas Escolares ganha uma outra perspectiva, a partir da pesquisa sobre certos objetos específicos como, por exemplo, a história dos cânones escolares, que pode auxiliar na compreensão da difusão das práticas de leitura da elite, ou a história da difusão do livro, que foi "clareada pela história dos mediadores culturais da escrita, vivendo no contato dos dois mundos, o do oral e o da escrita (padres, professores, notários etc.)" (p. 36). A História das Disciplinas Escolares pode, assim, ajudar a compreender qual o papel específico da escola na inserção de certos grupos em sociedades fortemente marcadas pela escrita (ou pela oralidade). Nas palavras de Hébrard (1999):

Assim, a escola forma, em seu espaço próprio, sujeitos que lêem, escrevem, mas tam-

10. Sobre o método intuitivo, ver Valdemarin (2004). 
bém ordenam o mundo conforme as categorias que o corpus de textos e a palavra do professor tornam quase naturais. Comunidade de interpretação inaugural, a escola é obrigada a produzir uma recepção compartilhada dos textos, pelo único fato de que, sem a certeza do sentido, não haveria nem ensino possivel, nem aprendizagem. As aprendizagens iniciais não são, portanto, como se acredita, saberes neutros, puramente instrumentais, prontos para servir a qualquer uso. Que leitores, que escritores tornam-se os ex-alunos quando encontram, longe da escola, as sociabilidades do trabalho, da família, da vizinhança? Que fazem com o equipamento mental de que a escola os dotou, com menos ou mais paciência ou violência? Como esquecê-lo ou transformá-lo para desenvolver novas habilidades, mais apropriadas às necessidades da vida social? Entre as figuras do leitor, cujas variantes a história cultural descreve e as figuras de escolares, que nós tentamos reconstruir aqui, existem desvios e continuidades cujos mecanismos nos escapam ainda. (p. 77)

Como afirmam Lopes e Galvão (2001): Influenciado, sobretudo pelos trabalhos realizados no âmbito da história cultural, o estudo das disciplinas e dos saberes escolares tem sido considerado fundamental para melhor compreender o papel dos contextos culturais na definição daquilo que deve ser ensinado na escola e, por outro lado, o papel da escola na produção e na reelaboração do conhecimento, principalmente através dos processos de didatização. (p. 55)

\section{Dois estudos em História das Disciplinas Escolares}

Nessa parte do artigo, descrevemos e discutimos brevemente dois trabalhos realizados recentemente por pesquisadores brasileiros no âmbito da História das Disciplinas Escolares.
Ambos se debruçam sobre disciplinas que, na atualidade, ocupam um espaço secundário no currículo escolar: a Educação Física e a Educação Artística. Além disso, os dois estudos se detêm sobre dimensões da vida de homens e mulheres que não estão diretamente relacionadas àquilo a que a escola tradicionalmente se propôs a trabalhar, ou seja, a atividade cognitiva, intelectual. Lidam, por outro lado, com o corpo e a sensibilidade. Ambos se referem a áreas da atividade humana que não constituem, fora da escola, a não ser muito recentemente, saberes propriamente científicos, com uma tradição epistemológica de longa data ${ }^{11}$.

No âmbito da historiografia em Educação Física, poderíamos sinteticamente configurar quatro grandes momentos/estágios dos estudos históricos dessa disciplina escolar, correndo o risco, mesmo não sendo essa a intenção, de sermos interpretados como reducionistas e lineares. Um primeiro momento, caracterizado como uma história dos ideários pedagógicos, tem como proeminentes autor e obra Fernando Azevedo (1960) - Da educação física: o que é, o que tem sido e o que deveria ser. Nessa história da Educação Física, tem-se muito mais a preocupação em legitimar uma posição no presente do que se empenhar em um conhecimento do passado (Pagni, 1995). Outro momento, configurado como uma história oficial e episódica, tem em Inezil Penna Marinho seu grande representante, com duas importantes obras analisadas pelos estudiosos História geral da Educação Física e Contribuição para a história da Educação Física no Brasil. Essa história da Educação Física faz estudos de longos periodos e a partir de documentos oficiais, coletados principalmente em um único local - os arquivos da Biblioteca Nacional (Pagni, 1995). Segundo Ferreira Neto (1996), representam “a visão dos de cima”, descrita de forma objetiva e linear. Em um outro momento, as pesquisas se fundamentam em uma concepção de história marxista: seu autor e obra de maior destaque é

11. Nesse sentido, a tese da transposição didática mostra, de partida, fragilidades para compreender esse tipo de disciplina. 
Lino Castellani Filho, com o trabalho Educação Física no Brasil: a história que não se conta (1988). Essa historiografia da Educação Física procura reescrever a história, a partir principalmente da identificação das relações socioeconômicas, objetivando opor-se a uma narrativa que apenas descreve e agrupa os acontecimentos, procurando interpretar os fatos diante de um movimento de resistências (Pagni, 1995). A história, nessa perspectiva, acontece e é escrita como expressão das relações sociais que, por sua vez, são consideradas como reflexo do modo de produção (Ferreira Neto, 1996). Em um outro momento, no qual se inclui a pesquisa de Vago (2002), os trabalhos voltam-se para a perspectiva da Nova História, destacando-se aqui os seguintes estudiosos e obras: Fernanda Paiva Ciência e poder simbólico no Colégio Brasileiro de Ciências do Esporte; Eustáquia de Souza - Meninos, à marcha ! Meninas, à sombra !; Victor Andrade de Melo - Escola Nacional de Educação Física e Desportos: uma possível história. Essa historiografia da Educação Física reconhece que toda atividade humana tem história e assim amplia o uso de fontes, procurando reconhecer "a visão dos de baixo" (Ferreira Neto, 1996).

0 primeiro estudo, resultado de uma tese de doutorado em Educação da Universidade de São Paulo, já publicado como livro, teve como título Cultura escolar, cultivo de corpos: Educação Physica e Gymnastica como práticas constitutivas dos corpos de crianças no ensino público primário de Belo Horizonte (19061920). Seu autor é Tarcísio Mauro Vago (2002), professor da Universidade Federal de Minas Gerais, membro do Grupo de Estudos e Pesquisas em História da Educação da Faculdade de Educação, também coordenador do Centro de Estudos e Pesquisas em Educação Física Escolar da Escola de Educação Física da mesma Universidade (ProEFE-EEF).

0 objetivo do estudo de Vago (2002), que expressa proximidade com a perspectiva mais recente de tradição de pesquisas no interior da historiografia da Educação Física, foi investigar a constituição do campo disciplinar
Gymnastica nas práticas escolares do ensino primário em Belo Horizonte a partir da reforma de 1906. 0 autor nos mostra como, nas duas primeiras décadas do século XX, a Educação Física, em meio às relações de conflitos e tensões, foi-se constituindo disciplina escolar em instituições públicas desse município, dando-nos referências para, uma vez mais, perceber que a história não acontece de maneira linear.

Seu problema de pesquisa partiu dos seguintes questionamentos: 1- Que representações de ginástica foram produzidas naquele momento em que se procurava implantar uma nova ordem escolar em Belo Horizonte? 2- Com base em que matrizes foram produzidas? 3- Que exercícios physicos foram prescritos nas diversas reformas do ensino primário promovidas no período? 4- Que corpo se desejava construir nas (e com as) práticas escolares?

Teve como referencial teórico-metodológico a Nova História Cultural e como categorias conceituais as definições de representação, de Roger Chartier; de documento, de Jacques Le Goff; de estratégia e tática, de Michel de Certeau; e de cultura escolar, de Dominique Julia. Suas principais fontes foram leis, programas escolares, relatórios, ofícios, cartas, mapas de pagamentos, folhas de presença, pesquisados no acervo do Arquivo Público Mineiro de Belo Horizonte.

Segundo Vago (2002), a Educação Física inicialmente, na forma de Ginástica, teve como tarefa, de maneira higiênica, "desinfetar e limpar" os corpos das crianças, tornando-os "belos, fortes e saudáveis", como também, de maneira corretiva, "endireitar" os corpos "defeituosos", "toscos”, "amarelados", indolentes, colocando-os em posição ereta e varonil. 0 autor nos mostra que, a partir dos anos de 1920, uma outra lógica passa a orientar a escolarização dessa disciplina, reconfigurando a correção dos corpos de princípios republicanos em direção à eficiência dos gestos necessários à industrialização. É claro que essas lógicas pautadas numa idéia de hegemonia cultural, presentes nas elites intelectuais, encontraram resistências na 
heterogeneidade das experiências dos atores sociais. As crianças, por exemplo, muitas vezes, respondiam a essas lógicas com fugas e infreqüência às sessões de aulas.

Aliás, Vago (2002) apresenta não só as diferentes lógicas, matrizes e concepções de corpo e educação presentes na prática da Educação Física no período estudado, mas a configuração da própria Educação Física como disciplina escolar, a partir de uma discussão, por exemplo, dos próprios termos que designavam essa parte dos programas escolares, que não se restringia a uma única disciplina. Exercícios Physicos, Exercícios Gymnasticos, Exercícios Calisthenicos ou simplesmente Gymnastica, juntamente com outras disciplinas, responsabilizavam-se pela Educação Physica das crianças. No entanto, com o passar do tempo, essa educação do físico dos meninos e meninas passa a ser de responsabilidade de uma disciplina específica a Educação Physica - que assumiria a tarefa do cultivo dos corpos.

O segundo estudo selecionado foi, por sua vez, resultado de uma dissertação de mes-trado em educação da Universidade Federal de Pernambuco, em que a autora, Maria Betânia e Silva, que é professora de Educação Artística na rede estadual de ensino, é também pesquisadora do Núcleo de Estudos e Pesquisas História da Educação em Pernambuco. Esse estudo, $A$ inserção da arte no currículo escolar (Pernam-buco, 1950-1980), foi por sua vez motivada por questões do presente, a autora assim justifica o seu estudo:

Como professora de arte, em escolas públicas e privadas há oito anos, tenho levantado uma série de questionamentos e buscado compreender o porquê de a existência de alguns preconceitos estabelecidos com relação à arte como disciplina curricular. 0 fato da arte ser posta sempre numa posição secundária em relação às outras disciplinas, o estigma criado entre alunos e professores de que 'arte não reprova', portanto, não é necessário ser levada a sério como as outras disciplinas e também à freqüente presença de profissionais de outras áreas, que lecionam a disciplina como complemento de carga horária, levaram-me a uma inquietação e as questões passaram a se intensificar. (Silva, 2004, depoimento oral gravado em áudio)

Entre as questões colocadas pela autora, destacam-se:

[...] por que a arte é relegada a um segundo plano como disciplina entre docentes e entre outros profissionais da instituição escolar?; por que se considera a arte apenas como complemento secundário e talvez desnecessário no currículo, que serve apenas para decoração do ambiente e comemoração de datas festivas ou é considerada apenas como uma atividade de lazer e, ainda, que a arte não é preciso 'ser pensada', logo não tem 'o peso' que as outras disciplinas têm porque não é preciso usar a 'razão'?; (...) por que qualquer profissional de qualquer área pode lecionar a arte, fato que não ocorre em relação à grande parte das outras disciplinas do currículo?; porque a carga horária é tão reduzida em relação às outras disciplinas?, enfim, por que não existe uma estruturação do conteúdo pro-gramático a ser trabalhado e desenvolvido como nas outras disciplinas? (Silva, 2004, depoimento oral gravado em áudio)

De maneira diferente do que ocorre em relação aos trabalhos sobre Educação Física, são praticamente inexistentes os trabalhos, no caso brasileiro, que se debruçam sobre a história da arte na escola, como indica a autora. Tal constatação já havia sido feita por Ana Mae Barbosa (1999) a partir de um levantamento realizado em 80 dissertações e teses no Brasil.

Silva (2003) fundamentou-se teórica e metodologicamente na Nova História Cultural, tendo como referências os estudos de Jacques Le Goff, Jean Hébrard e Michel de Certeau. Baseou-se ainda na compreensão de História das Disciplinas Escolares de André Chervel, Circe Bittencourt, Dominique Julia e lvor 
Goodson. Utilizou como fontes de pesquisa legislação (leis, resoluções, pareceres), propostas curricu-lares e programas de ensino, jornais e revistas, assim como depoimentos orais. Para selecionar tais fontes, pesquisou nos acervos do Arquivo Público Estadual de Pernambuco, da Biblioteca do Centro de Artes e Comunicação da UFPE, da Biblioteca Pública do Estado de Pernam-buco, do Conselho Estadual de Educação e da Divisão de Extensão Cultural e Artística - DECA.

Silva (2004) constata que, embora a Arte esteja presente no currículo escolar brasileiro desde o século XIX - com outras denominações e, em alguns casos, no interior de outras disciplinas -, é somente durante a ditadura militar (a partir da Lei 5.692/71) que esta vira disciplina escolar obrigatória - com a denominação de Educação Artística. A autora estuda, então, o papel desempenhado por alguns movimentos e instâncias que contribuíram para a articulação dos profissionais da área - que associa aos fatores internos caracterizados por Santos (1990) - e o próprio processo de elaboração da lei, naquele contexto histórico específico - busca compreender, assim, o papel dos fatores externos na criação/transformação de uma disciplina.

Como podemos constatar, estudos como os aqui referidos podem elucidar uma série de questões que estão no centro do debate educacional contemporâneo. Acreditamos que compreender melhor como um saber se escolariza em determinados momentos da história, que relações estabelecem com práticas sociais não escolares e como a escola inventa e reinventa, em seu interior, outros saberes e torna legítimos os seus usos, certamente auxiliam a entender o papel que vem sendo desempenhado pela instituição escolar ao longo da história.

\section{Consideraçōes finais}

0 processo de escolarização da cultura, ou seja, a transformação dos saberes em saberes propriamente escolares, existente em dife- rentes períodos históricos, é o elemento central nas pesquisas do campo da História das Disciplinas Escolares. Essa tendência revela uma nova maneira de olhar o passado educacional das instituições de ensino, oferecendo uma nova leitura das fontes, fornecendo elementos para melhor perceber e compreender a construção cultural do cotidiano escolar.

Neste artigo, pensamos ter sido possível fornecer alguns elementos para a reflexão em torno da História das Disciplinas Escolares a partir dos processos de renovação e ampliação observados na área de História da Educação no Brasil. Apesar do crescente número de pesquisas realizadas em torno do tema, no entanto, observamos que ainda há muito a ser investigado. Em relação às disciplinas Educação Física e Educação Artística, por exemplo, aqui citadas, muitas vezes vemos estudos que se debruçam sobre a história da arte ou das práticas corporais como dimensões das manifestações culturais da humanidade, como se fossem sinônimos da história desses saberes escolares. No entanto, essas histórias necessariamente não expressam a história de seus saberes escolares. A escolarização das artes e das práticas corporais mantém relação de fato com essas dimensões da cultura humana, mas, como mostra a História das Disciplinas Escolares, é necessário perceber e compreender as particularidades da escolarização desses saberes e práticas nos diferentes tempos e espaços sociais. A história da arte e a história das práticas corporais não se confundem e não coincidem, portanto, com a história da Educação Artística e a história da Educação Física. Mesmo mantendo relações entre si, essas histórias possuem características peculiares em cada espaço social e em cada época.

A constituição dos saberes escolares específicos a cada disciplina do currículo é resultado de um processo complexo que envolve consentimentos, conflitos, diferentes tipos de mediação entre diversos sujeitos e instituições, diante dos papéis que, em cada época e sociedade, são atribuídos à escola. Na Educação Física e na Educação Artística, contemporaneamente, esse processo 
parece marcado por uma busca permanente de legitimidade diante de saberes que, tradicionalmente, parecem mais próximos ao que foi sendo identificado (e naturalizado) como inerente à instituição escolar: saberes mais próximos da racionalidade moderna.

Por fim, cabe ressaltar que, apesar do grande número de pesquisas que vêm sendo realizadas na área, a maioria dos trabalhos, muitas vezes dedicados a traçar cronológica e retroativamente a presença de um saber na escola, é realizada de forma isolada. Além disso, muitos deles já partem de pressupostos - mais ou menos rígidos - advindos das tradições da transposição didática ou da cultura escolar - tomadas como "partidos" ou "profissões de fé" opostos e inconciliáveis -, o que, ao invés de auxiliar a elucidar os processos que tornam possível a existência de saberes e disciplinas propriamente escolares, torna a realidade educacional do passado ainda mais opaca. Acreditamos que somente com a realização periódica de balanços ou estados da arte é possível tornar inteligível o processo de transformação e/ou construção de saberes em saberes propriamente escolares tan- to do ponto de vista empírico quanto do ponto de vista propriamente teórico. A tarefa de responder, empirica-mente, algumas questões básicas - como: quando determinada disciplina passa a compor a grade curricular das escolas públicas? Mesmo ausentes como disciplinas escolares, esses saberes/práticas estavam presentes na escola? Que agentes e fatores sociais tornaram possíveis essa inserção? - já é extremamente complexa em um país com as dimensões do Brasil onde, por exemplo, durante o século XIX e nas primeiras décadas do XX, cada província/estado tinha uma legislação e uma estruturação curricular próprias. Em uma perspectiva teórica, acreditamos que esses balanços periódicos possam elucidar questões como as relações estabelecidas entre saberes/práticas escolares e não escolares, entre aspectos políticos, sociais e econômicos e escola, entre cultura popular e cultura erudita, entre transposição didática e cultura escolar, em um país de esco-larização tardia e profundamente marcado pelas presenças do manuscrito e da oralidade e pelas distinções sociais, raciais/étnicas, regionais, geracionais e de gênero.

\section{Fontes citadas (manuscritas)}

APEJE (Arquivo Público Estadual Jordão Emerenciano - Pernambuco):

I.P. 19 - série Instrução Pública. Directoria Geral da Instrucção Publica. Pareceres do Conselho Literário. 1866. Documentação Avulsa.

I.P. 44 - série Instrução Pública. Inspectoria Geral da Instrucção Publica. Pareceres do Conselho Literário. 1885. Documentação Avulsa.

\section{Referências bibliográficas}

AZEVEDO, F. Da educação física: o que é, o que tem sido e o que deveria ser. São Paulo: Edições Melhoramentos, 1960.

AMADO, J.; FERREIRA, M. de M. (Orgs.). Usos e abusos da história oral. Rio de Janeiro: Editora da Fundação Getúlio Vargas, 1996.

BARBOSA, A. M. (Org.). Arte-educação: leitura no subsolo. São Paulo: Cortez, 1999.

BITTENCOURT, C. M. F. Disciplinas escolares: história e pesquisa. In OLIVEIRA, M. A. T. de; RANZI, S. M. F. (Orgs.). História das disciplinas escolares no Brasil: contribuições para o debate. Bragança Paulista: EDUSF, 2003. 
BURKE, P. A Escola dos Annales (1929-1989): a Revolução Francesa da historiografia. São Paulo: FEU, 1997.

CARVALHO, M. M. C. de. Revisitando a historiografia educacional brasileira. In: MENEZES, M. C. (Org.). Educação, memória, história: possibilidades, leituras. Campinas: Mercado de Letras, 2004.

CASTELLANI FILHO, L. Educação física no Brasil: a história que não se conta. Campinas: Papirus, 1988.

CHARTIER, R. A história cultural: entre práticas e representações. Lisboa: DIEFEL, 1990.

CHERVEL, A. História das disciplinas escolares: reflexões sobre um campo de pesquisa. Teoria e Educação. Porto Alegre, $n^{0} 2$, p. 177-229, 1990.

CHEVALLARD, Y. La transposition didactique: du savoir savant au savoir enseigné. Grenoble: La Pensée Sauvage, 1985.

COMPÈRE, M.-M. L'histoire de l'éducation en Europe: essai comparatif sur la façon dont elle s'écrit. Paris: INRP/Peter Lang, 1995.

FARIA FILHO, L. M. de. Dos pardieiros aos palácios: cultura escolar e urbana em Belo Horizonte na Primeira República. Passo Fundo: Editora da Universidade de Passo Fundo, 2000.

FARIA FILHO, L. M. de, VIDAL, D. G. Os tempos e os espaços escolares no processo de institucionalização da escola no Brasil. Revista Brasileira de Educação, Rio de Janeiro, n. 14, p. 19-34, maio/ago. de 2000.

FERREIRA NETO, A. Pesquisa histórica na Educação Física brasileira. In: brasileira. Vitória: CEFD/UFES, 1996, p. 5-32. (Org.). Pesquisa histórica na Educação Física

FORQUIN, J.-C. Saberes escolares, imperativos didáticos e dinâmicas sociais. Teoria e Educação. Porto Alegre, n. 5, p. 28-49, 1992.

. As abordagens sociológicas do currículo: orientações teóricas e perspectivas de pesquisa. Educação \& Realidade, Porto Alegre, n. 21(1), p. 187-198, jan./jun. 1996.

GALVÃO, A. M. de 0. et al. Livros escolares de leitura: caracterização e usos (Pernambuco, século XIX). Relatório Final de Pesquisa apresentado ao CNPq. Recife, 2003 (mimeo.).

GOODSON, I. F. Currículo: teoria e história. Rio de Janeiro: Vozes, 1995.

HÉBRARD, J. Três figuras de jovens leitores: alfabetização e escolarização do ponto de vista da história cultural. In: ABREU, M. (Org.). Leitura, história e história da leitura. Campinas: Mercado de Letras, 1999.

HENRY, M. Apresentação da Didática da Matemática. Notas de curso sobre Didática da Matemática. (Trad. Lícia de Souza Leão Maia). São Paulo: PUC, 1992 (mimeo.).

HOBSBAWN, E., RANGER, T. (Orgs.) A invenção das tradições. Rio de Janeiro: Paz e Terra, 1984.

JULIA, D. A cultura escolar como objeto histórico. Revista Brasileira de História da Educação. Campinas, n. 1, p. 9-43, jan./ jun., 2001.

LE GOFF, J. História e memória. Campinas: EDUNICAMP, 1994.

LOPES, E. M. T.; GALVÃO, A. M. de 0. História da educação. Rio de Janeiro: DP\&A, 2001.

MARINHO, I. P. Contribuição para a história da Educação Física no Brasil: Brasil colônia - Brasil império - Brasil república. Rio de Janeiro: Imprensa Nacional, 1943.

História geral da Educação Física. São Paulo: Companhia Brasil Editora, 1980.

MELO, V. A. de. Escola Nacional de Educação Física e Desportos: uma possível história. Dissertação (Mestrado), UNICAMP, Campinas. 1996. 
MOREIRA, A. F. B. e SILVA, T. T. da. (Org.). Currículo, cultura e sociedade. São Paulo: Cortez, 1995.

OLIVEIRA, B. J. de. Imaginário científico e a História da Educação. In: FONSECA, T. N. de L.; VEIGA, C. G. História e historiografia da educação no Brasil. Belo Horizonte: Autêntica, 2003, p. 101-128.

PAGNI, P. Â. História da Educação Física no Brasil: notas para uma avaliação. In: FERREIRA NETO, A.; GOELLNER, S.; BRACHT, V. (Orgs.). As ciências do esporte no Brasil. Campinas: Autores Associados, 1995. p. 149-163.

PAIVA, F. Ciência e poder simbólico: no Colégio Brasileiro de Ciências do Esporte. Vitória: UFES/CEFD, 1994.

PINHEIRO, A. C. F. Da era das cadeiras isoladas à era dos grupos escolares na Paraíba. Campinas: Autores Associados; Bragança Paulista: Editora da Universidade de São Francisco, 2002.

SANTOS, L. L. de C. P. História das disciplinas escolares: perspectivas de análises. Teoria e Educação. Porto Alegre, n. 2, p. 21-29, 1990.

SAVIANI, N. Saber escolar, currículo e didática: problemas da unidade conteúdo/método no processo pedagógico. Campinas: Autores Associados, 1994.

SILVA, M. B. e. A inserção da arte no currículo escolar: Pernambuco, 1950-1980. Dissertação (Mestrado), UFPE, Recife. 2003.

SOUZA, E. S. de. Meninos, à marcha! Meninas, à sombra! Tese (Doutorado), UNICAMP, Campinas. 1994.

SOUZA, R. F. de. Templos de civilização: a implantação da escola primária graduada no estado de São Paulo (1890-1910). São Paulo: UNESP, 1998.

VAGO, T. M. Cultura escolar cultivo de corpos: Educação Physica e Gymnastica como práticas constitutivas dos corpos de crianças no ensino público primário de Belo Horizonte (1906-1920). Bragança Paulista: EDUSF, 2002.

VALDEMARIN, V. Estudando as lições de coisas: análise dos fundamentos filosóficos do método de ensino intuitivo. Campinas: Autores Associados, 2004

VIDAL, D. G., FARIA FILHO, L. M. de. História da educação no Brasil: a constituição histórica do campo (1880-1970). Revista Brasileira de História, São Paulo, v.23, n.45, p.37-70, 2003.

Recebido em 07.03 .05

Aprovado em 09.06.05

Marcílio Souza Júnior é professor da Universidade de Pernambuco (UPE), membro do Grupo de Estudos Etnográficos em Educação Física e Esportes (ETHNÓS) do Laboratório de Estudos Pedagógicos do Centro de Estudos em Educação Física e Esportes da Escola Superior de Educação Física. Doutorando em Educação, membro da Linha de Pesquisa de Formação de Professores e Prática Pedagógica do Programa de Pós-Graduação da UFPE.

Ana Maria de Oliveira Galvão é professora da Faculdade de Educação da Universidade Federal de Minas Gerais (UFMG). Doutora em Educação pela UFMG. Pesquisadora do CNPq, do Núcleo de Estudos e Pesquisas História da Educação em Pernambuco (NEPHEPE/UFPE) e do Centro de Alfabetização, Leitura e Escrita (CEALE/UFMG). 